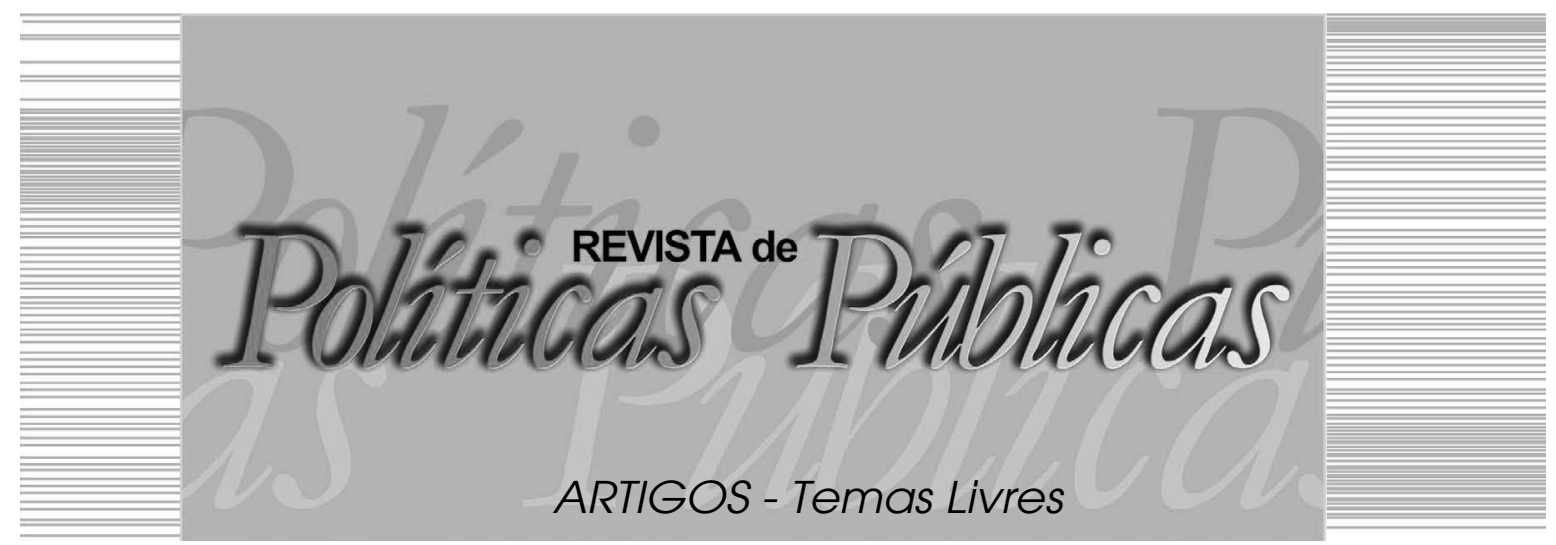

\title{
A POLITICA NACIONAL DE RESIDUOS SÓLIDOS E A ESTRATÉGIA DE FORMAÇÃO DE CONSÓRCIOS PÚBLICOS INTERMUNICIPAIS
}

\author{
Nathalia Machado Simãol \\ Francisco César Dalmo ${ }^{2}$ \\ Silvia Azucena Nebra ${ }^{3}$ \\ Paulo Henrique de Mello Sant'ana
}

\section{Resumo}

Com a publicação da Política Nacional de Resíduos Sólidos (PNRS) em 2010, o artigo identifica a necessidade de coordenação técnica, política, econômica e socioambiental para a gestão de Resíduos Sólidos Urbanos (RSU) no Brasil. Considera que essa gestão é de incumbência municipal, e que a maior parte dos municípios brasileiros é de pequeno porte, logo, não possui capacidade técnica e financeira para realizar o manejo adequado dos RSU. Dessa forma, este artigo apresenta os resultados da pesquisa referente ao mapeamento dos

\footnotetext{
Graduada em Administração, Doutora em Energia pela Universidade Federal do ABC (UFABC), Pós Doutoranda pela UFABC. Email: nathalia.simao@ufabc.edu.br

2 Engenheiro Hídrico, Doutorando em Energia pela UFABC, Professor da Universidade Federal dos Vales do Jequitinhonha e Mucuri (UFVJM). Email: francisco. dalmo@ufvjm.edu.br / Universidade Federal dos Vales do Jequitinhonha e Mucuri - UFVJM: Rua do Cruzeiro, $\mathrm{n}^{\circ}$ 01, Bairro Jardim, São Paulo Teófilo Otoni - MG. CEP: 39803-371

3 Graduação e Licenciatura em Física, Mestre e Doutora em Engenharia Mecânica pela Universidade Estadual de Campinas (UNICAMP), Professora Visitante Senior da UFABC. Email: silvia.nebra@ufabc.edu.br

4 Engenheiro Mecânico, Doutor em Planejamento de Sistemas Energéticos pela UNICAMP, Professor da UFABC. Email: paulo.santana@ufabc.edu.br / Universidade Federal do ABC - UFABC: Avenida dos Estados, 5001 - Bairro Santa Terezinha - Santo André. CEP: 09210-580
} 
consórcios públicos intermunicipais da área ambiental no Estado de São Paulo, no intuito de que esta caracterização estimule estudos futuros acerca de novas abordagens de arranjos municipais, e que sejam adotadas outras soluções de tratamento e destinação final dos resíduos, além da simples disposição final nos aterros sanitários.

Palavras-chave: Resíduos sólidos urbanos, arranjos intermunicipais, consórcios públicos.

\title{
NATIONAL POLICY ON SOLID WASTE AND THE STRATEGY OF PUBLIC CONSORTIUMS FORMATION
}

\begin{abstract}
The publication of the National Policy on Solid Waste (PNRS) in 2010 identified the need of the technical, political, economic and socio-environmental coordination for the management of Municipal Solid Waste (MSW) in Brazil. Whereas that management is responsibility of the municipalities, and the most of these are small-sized, they do not have the technical and financial capacity to carry out the proper management of their MSW. Therefore, this paper presents the results of the research concerning the mapping of the environmental intermunicipal public consortia in the State of São Paulo. It is also expected that the characterization stimulate future studies on new approaches to local arrangements, and other treatment solutions and disposal of waste is adopted, besides the simple final disposal in landfills.
\end{abstract}

Key words: Municipal solid waste, intermunicipal arrangements, public consortiums.

\section{INTRODUÇÃO}

De acordo com o Panorama dos Resíduos Sólidos no Brasil (ASSOCIAÇÃO BRASILEIRA DE EMPRESAS DE LIMPEZA PÚBLICA E RESÍDUOS ESPECIAIS, 2014) somente 40,2\% ${ }^{1}$ dos municípios brasileiros utilizam os aterros sanitários como prática de tratamento de Resíduos Sólidos Urbanos (RSU). Os 59,8\% restantes correspondem aos municípios que destinam os RSU em vazadouros a céu aberto, os locais conhecidos como lixões, onde não há nenhum tipo de gestão ou controle ou em aterros controlados - onde alguns princípios são empregados, mas a gestão e o tratamento dos RSU não são adequados como no caso dos aterros sanitários. Em relação à destinação final do volume total dos resíduos coletados, a mesma pesquisa (ASSOCIAÇÃO BRASILEIRA DE EMPRESAS DE LIMPEZA PUBBLICA E RESÍDUOS ESPECIAIS, 2014) revelou que $58,4 \%$ tiveram destinação adequada e seguiram para aterros 
sanitários em 2014. Isso significa, segundo o Panorama, que $81 \mathrm{mil}$ toneladas diárias (referentes aos $41,6 \%$ restantes) foram encaminhadas aos lixões ou aterros controlados. A pesquisa da Associação Brasileira de Empresas de Limpeza Pública e Resíduos Especiais (ABRELPE, 2014) atingiu um universo de 400 municípios, ou seja, $7,18 \%$ do total dos municípios brasileiros.

O Diagnóstico do Manejo de Resíduos Sólidos Urbanos - 2014 do Sistema Nacional de Informações sobre Saneamento (SNIS) mostra que 52,4\% dos resíduos sólidos domiciliares coletados no país têm como destino final os aterros sanitários. O restante está dividido entre aterros controlados (13,1\%), em lixões (12,3\%), unidades de triagem e de compostagem $(3,9 \%)$ e, por fim, a massa sem informação (18,3\%). (BRASIL, 2016). A amostragem de municípios pesquisados pelo SNIS representa $67,6 \%$ do total dos municípios brasileiros, ou seja, 3.765 dos 5.570 responderam à pesquisa. (BRASIL, 2016).

De acordo com a Lei $\mathrm{n}^{0} 12.305$, e 2 de agosto de 2010 que institui a Política Nacional de Resíduos Sólidos (PNRS) e o Decreto Federal $\mathrm{n}^{\mathrm{o}} 7.404$, de 23 de dezembro de 2010 que a regulamenta, ficou determinado no artigo $55^{\circ}$, que a partir de 03/08/2010 (data de publicação do Decreto no Diário Oficial da União - DOU) a disposição final ambientalmente adequada dos rejeitos deveria ter sido implantada até 2014.

No entanto "[...] o objetivo - referindo-se à PNRS - não foi alcançado, fazendo com que ainda seja registrada a utilização de lixões em todas as regiões do país." (ASSOCIAÇÃO BRASILEIRA DE EMPRESAS DE LIMPEZA PUBBLICA E RESÍDUOS ESPECIAIS, 2014).

De acordo com PNRS ao Estado cabe, dentre outras funções, "[...] promover a integração da organização, do planejamento e da execução das funções públicas de interesse comum relacionadas à gestão dos resíduos sólidos nas regiões metropolitanas, aglomerações urbanas e microrregiões." (BRASIL, 2010, p. 4). Aponta também a necessidade de apresentar "[...] medidas para incentivar e viabilizar a gestão consorciada ou compartilhada dos resíduos sólidos", além de "[...] apoiar e priorizar as iniciativas do município de soluções consorciadas ou compartilhadas entre dois ou mais municípios.” (BRASIL, 2010, p. 4). 
Aos municípios, por sua vez, foi requerida a apresentação dos Planos Municipais que dentre outras exigências de conteúdo mínimo deveria identificar as possibilidades de "[...] implantação de soluções consorciadas ou compartilhadas com outros Municípios, considerando, nos critérios de economia de escala, a proximidade dos locais estabelecidos e as formas de prevenção dos riscos ambientais.” (BRASIL, 2010, p. 5). Indica também que serão priorizados no acesso aos recursos da União ou nos incentivos e financiamentos de entidades federais de crédito ou fomento, os municípios que "[...] optarem por soluções consorciadas intermunicipais para a gestão dos resíduos sólidos, incluída a elaboração e implementação de plano intermunicipal, ou que se inserirem de forma voluntária nos planos microrregionais de resíduos sólidos." (BRASIL, 2010, p. 5).

No caso do Estado de São Paulo, a necessidade de se pensar soluções conjuntas é evidente, justamente porque a maior parte dos municípios é de pequeno porte, e a gestão individualizada seria técnica e financeiramente inviável.

Assim, considerando as exigências da PNRS, bem como a necessidade de articulação intermunicipal para ganhos de escala e eficiência de gestão, o principal objetivo desta pesquisa é apresentar um diagnóstico da situação atual na gestão de RSU no Estado de São Paulo, evidenciando, principalmente, o levantamento dos consórcios paulistas já formados e ativos na área ambiental (incluindo saneamento, resíduos, recursos hídricos, entre outros). Serão apresentados, também, os locais de destinação final dos municípios do Estado de São Paulo bem como a geração total de resíduos e população de cada um dos consórcios identificados.

\section{CONTEXTUALIZAÇÃO}

\subsection{Formação de Consórcios Intermunicipais}

Para a formação dos consórcios públicos, os municípios devem se adequar à Lei $\mathrm{n}^{\circ} 11.107$, de 6 de abril de 2005 , que dentre outras exigências, indica que o consórcio público deverá ser constituído por " [...] contrato cuja celebração dependerá da prévia subscrição de protocolo de intenções." (BRASIL, 2005, p. 1) e onde os objetivos são determinados pelos entes federativos, de forma horizontal entre munícipio/munícipio ou estado/estado ou de forma vertical en- 
tre munícipio/estado ou munícipio, estado e União. (BRASIL, 2005; SILVA, 2015).

Também é necessário que cada uma das partes consorciadas (no caso os municípios) tenham previamente autorizadas as leis $\mathrm{Mu}-$ nicipais que lhes permitam a participação em consórcios. Após essas duas etapas, segue-se a definição do Estatuto do Consórcio, a obtenção do Cadastro Nacional de Pessoa Jurídica (CNPJ), a abertura da conta bancária e a elaboração dos contratos de rateio e de programa. públicos.

A Figura 1 apresenta as etapas para a formação de consórcios

Figura 1 - Etapas para a formação de consórcios públicos

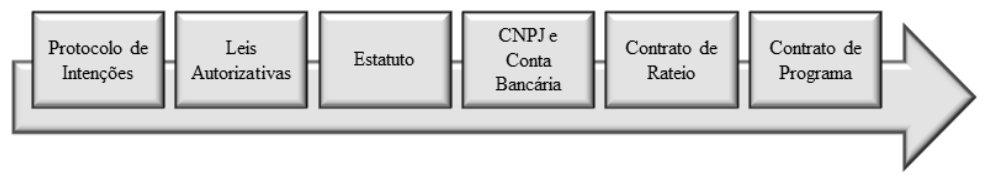

Fonte: Adaptado de: MINAS GERAIS. Secretaria de Estado de Desenvolvimento Regional, Política Urbana e Gestão Metropolitana. Relatório de Consórcios de Resíduos Sólidos Urbanos de Minas Gerais. Belo Horizonte, mar. 2016. Disponível em:<http://www.cidades.mg.gov.br/images/ NOTICIAS/2016/Relatrio\%20da\%20pesquisa\%20com\%20consrcios\%20de\%20RSU\%20-\%20 verso\%20pdf.pdf $>$. Acesso em: 5 set. 2016.

$\mathrm{Na}$ década de 80 as políticas de descentralização deram ênfase aos consórcios, que, antes disso, eram estruturas quase que desconhecidas. Mesmo depois da Constituição de 1988 "'[...] continuaram a ser considerados meros pactos de colaboração ou cartas de boas intenções, que não geravam compromissos e não precisavam ser obrigatoriamente cumpridos." (INSTITUTO BRASILEIRO DE GEOGRAFIA E ESTATÍSTICA, 2012, p. 42).

Antes da publicação da Lei ${ }^{\circ} 11.107 / 2005$ havia certo consenso de que os consórcios públicos, assim como os convênios de cooperação, não adquiriam personalidade jurídica, mas sim que se configuravam como figura estratégica e se concentravam em discutir a melhor forma de administrar e potencializar a capacidade do setor público na execução de políticas relacionadas ao consórcio. Tratava-se de "[...] acordos de vontades para a consecução de bens comuns." onde a melhor solução seria a de criar-se uma comissão executiva no intuito de assumir direitos e obrigações da gestão em nome de uma das pessoas jurídicas que compunham o consórcio. (DI PIETRO, 2005, p. 2). 
O Instituto Brasileiro de Geografia e Estatística (IBGE, 2015, p. 37) considera que os consórcios públicos exercem "[...] papel proeminente como instrumento de articulação para o desenvolvimento de políticas públicas". A formalização pela Lei no 11.107/2005 traz a possibilidade de se estabilizar as vantagens da formação de consórcios públicos considerando que:

Constituem-se em alternativa importante para melhorar a eficiência da prestação de serviços públicos e têm possibilitado a discussão de um planejamento regional em quesitos como a ampliação da oferta de serviços por parte dos municípios, a racionalização de equipamentos, a ampliação de cooperação regional, a flexibilização dos mecanismos de aquisição de equipamentos e de contratação de pessoal, entre outras vantagens. (INSTITUTO BRASILEIRO DE GEOGRAFIA E ESTATÍSTICA, 2015, p. 37).

Nascimento Neto e Moreira (2012, p. 258) também destacam que a formação dos consórcios traz benefícios para os municípios, entre os quais:

[...] alinhamento do planejamento local e regional; auxílio da organização de planos, avaliações e indicadores; superação de problemas locais, possibilitado ganhos de escala; modernização de procedimentos administrativos; aumento da capacidade de cooperação técnica; implementação e regulação de políticas públicas regionalizadas; racionalização no uso de recursos financeiros, humanos e tecnológicos.

Dentre os municípios brasileiros que declararam participar de consórcio público, houve aumento de 88,1\% (2.903 municípios) em 2011 para 96,7\% (3.571 municípios) em 2015; isso, no que se refere aos envolvidos em cooperação horizontal, isto é, consórcio intermunicipal. (INSTITUTO BRASILEIRO DE GEOGRAFIA E ESTATÍSTICA, 2015).

De acordo com o IBGE (2012), no ano de 2011 85,6\% dos municípios do Estado de São Paulo possuíam alguma articulação interinstitucional. Nas publicações posteriores do IBGE entre 2013 e 2015, os dados por unidades de federação não são apresentados.

Segundo a série histórica publicada em 2015 (ano base 2013) pelo SNIS, de 3.572 municípios brasileiros pesquisados, apenas 639 faziam parte de algum consórcio, o que representa um percentual de 18\% dos municípios. (BRASIL, 2015). Nota-se que esse valor é baixo, considerando que o Brasil possui 5.570 municípios. 
No caso do Estado de São Paulo, esses valores representam 97 municípios de um total de 645 , ou seja, foi verificado que somente $15,03 \%$ dos municípios estavam envolvidos em algum tipo de consórcio. (BRASIL, 2015).

Nesse contexto, 569 municípios apresentam (INSTITUTO BRASILEIRO DE GEOGRAFIA E ESTATÍSTICA, 2015) população menor do que 100 mil habitantes, ou seja, $88,21 \%$ dos municípios do Estado. Assim, nos municípios que apresentam menor população, a gestão consorciada torna-se não só necessária, como imprescindível para lidar com a questão relativa aos RSU. O Diagnóstico de 2014 (BRASIL, 2016), entretanto, não apresentou dados sobre consórcios públicos para gestão de resíduos.

Corroborando o que indica a PNRS, a formação de consórcios municipais aumenta a capacidade de diálogo e negociação para a resolução de problemas, e em municípios de pequeno porte essas vantagens acentuam-se. (SUZUKI; GOMES, 2009). Além disso, a opção pela gestão de RSU, a partir dos consórcios públicos, é mais indicada devido aos ganhos de escala e minimização dos custos. A gestão por consórcios garante também maior racionalização de recursos tecnológicos, otimização na contratação de serviços, agilidade na execução da operação e demais ganhos técnicos, gerenciais e financeiros. Traz também outras vantagens, como o desenvolvimento de políticas regionalizadas.

Por outro lado, Anjos (2014) comenta a existência de algumas barreiras para a formação de consórcios públicos de resíduos sólidos. Cita a influência de questões político-partidárias além de conflitos e interesses municipais, bem como a necessidade de avaliar viabilidades técnica e econômica. Como no geral os municípios apresentam sistemas heterogêneos, indica também como alternativa mais viável para implementação dos consórcios, tratar inicialmente da disposição final para somente depois avaliar outras atividades a serem incorporadas. (ANJOS, 2014).

\subsection{A Proposta do Plano de Resíduos Sólidos do Estado de São Paulo}

O Plano de Resíduos Sólidos do Estado de São Paulo (PRS-SP) apresentou um levantamento de 2012 referente a todos os consórcios públicos do Estado de São Paulo. (SMA, 2014). O resultado foi apresentado em dois mapas (dos consórcios com até 19 municí- 
pios e dos consórcios de mais de 19 municípios) e estão reproduzidos nas Figuras 2 e 3 respectivamente.

Figura 2 - Consórcios identificados pelo PRS-SP com até 19 municípios

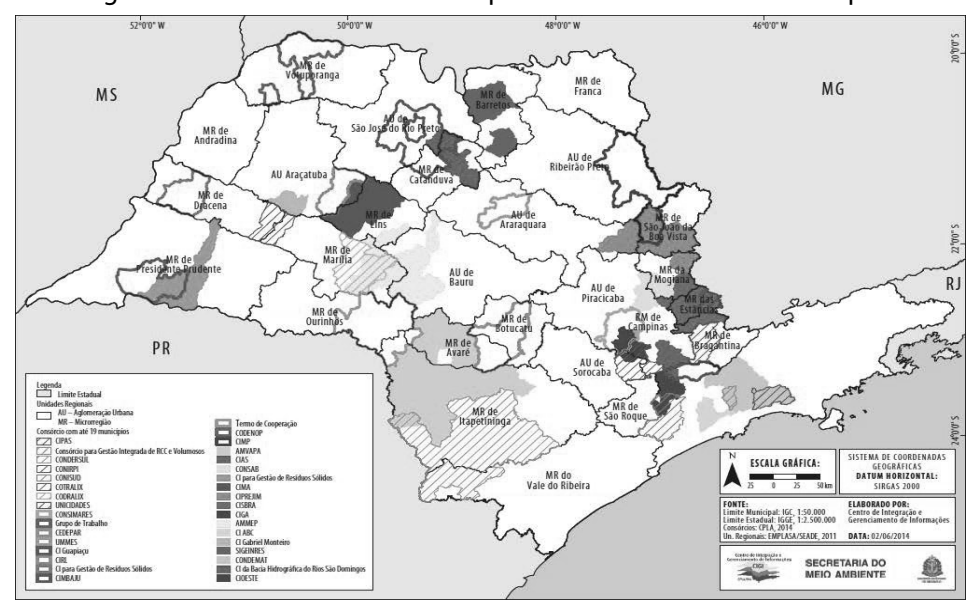

Fonte: SÃO PAULO. Secretaria do Meio Ambiente. Plano de resíduos sólidos do Estado de São Paulo. Organizadores André Luiz Fernandes Simas, Zuleica Maria de Lisboa Perez. 1. ed. São Paulo: SMA, 2014.

Figura 3 - Consórcios identificados pelo PRS-SP com 20 ou mais municípios integrantes

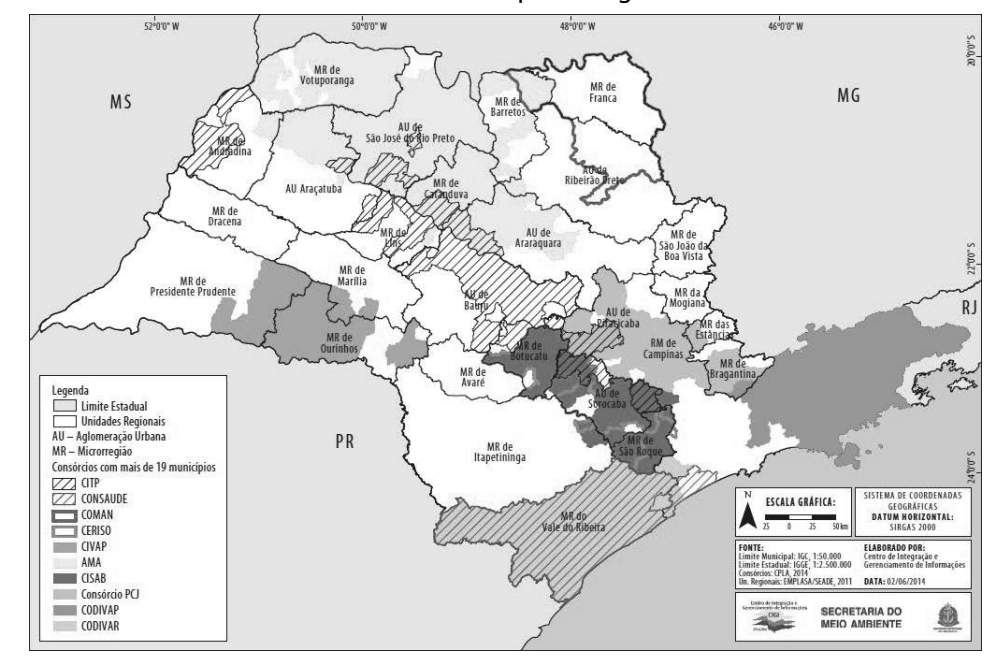

Fonte: (SÃO PAULO, 2014). 
Na ocasião, o PRS-SP realizou também um estudo que incluiu uma proposta de arranjo intermunicipal para a Gestão de RSU no Estado de São Paulo.

Como exemplo comparativo, vale citar a divisão dos arranjos territoriais ótimos (ATOs) realizada pelo Estado de Minas Gerais. (MINAS GERAIS, 2016). Na pesquisa de Felicori e outros (2016) ficou evidente a importância da existência prévia dessa delimitação que serviu como um dos critérios para a identificação de áreas adequadas para a construção de aterros sanitários e usinas de triagem e compostagem no Estado.

No caso de São Paulo, as discussões para as soluções em gestão de RSU basearam-se na publicação apresentada pela Rede Urbana e Regionalização do Estado de São Paulo², apresentada na Figura 4.

Figura 4 - Unidades regionais do Estado de São Paulo 2010

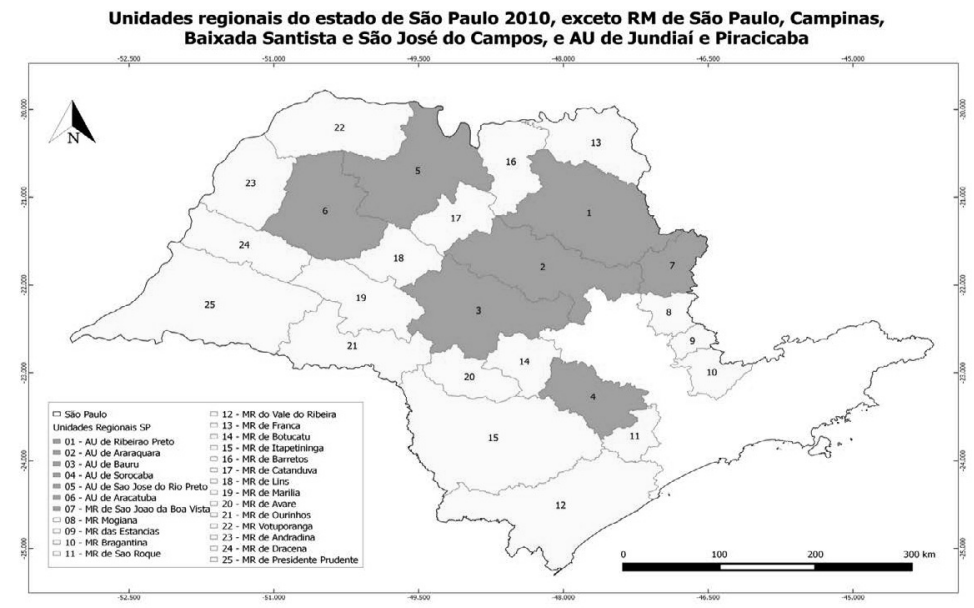

Fonte: Adaptado de EMPLASA (2011) e SMA (SÃO PAULO, 2014).

De acordo com o PRS-SP, para a proposta de arranjos intermunicipais apresentada, além da proposta de regionalização da EMPLASA (2011), foram também considerados critérios como a faixa de população associada às taxas de geração de resíduos, a logística e a malha viária, os municípios com população acima de 100.000 habitantes e os arranjos intermunicipais já existentes. (Figura 5). 
O PRS-SP ressalta ainda que a sugestão apresentada envolveu outros fatores como afinidades político-ideológicas, infraestruturas de tratamento e disposição finais já estabelecidos (SÃO PAULO, 2014). Dentre as sugestões presentes no PRS-SP para cada AU e Microrregiões (MR) selecionamos aqui as relativas às de agrupamento entre tais regiões conforme a Tabela 1.

Figura 5 - Proposição de Arranjos Intermunicipais do Plano Estadual de Resíduos Sólidos de São Paulo

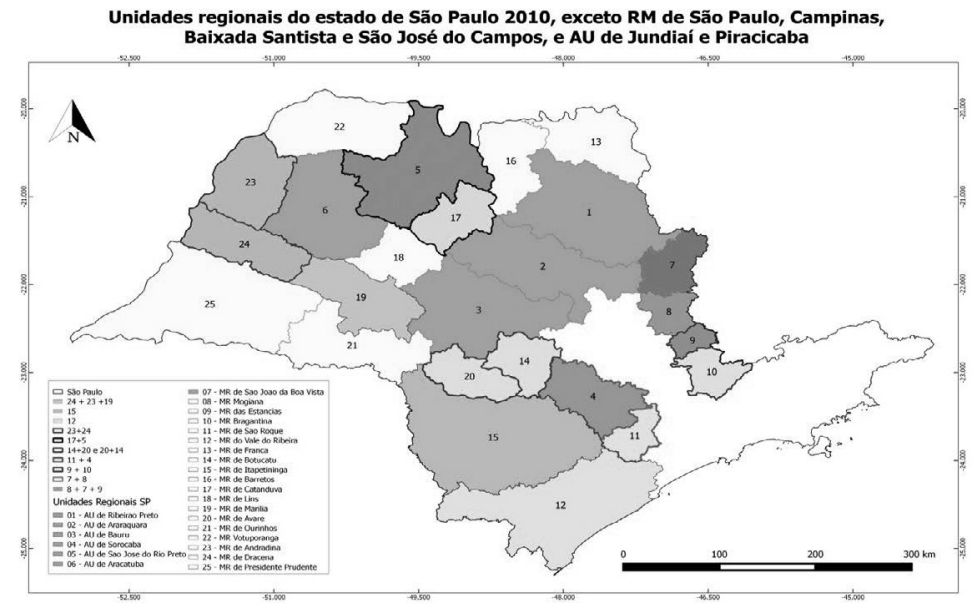

Fonte: Adaptado de EMPLASA (2011) e SMA (SÃO PAULO, 2014).

Tabela 1 - Proposição de soluções compartilhadas para as unidades regionais

\begin{tabular}{l|l}
\hline Unidades Regionais & Descrição das Soluções \\
\hline 1 -AU Ribeirão Preto & Entre os municípios da própria AU. \\
\hline 2 -AU Araraquara & Entre os municípios da própria AU. \\
\hline 3-AU Bauru & Entre os municípios da própria AU. \\
\hline 4-AU Sorocaba & Entre os municípios da própria AU. \\
\hline $\begin{array}{l}\text { P-AU São José do Rio } \\
\text { Preto }\end{array}$ & Entre os municípios da própria AU. \\
\hline $6-$ AU Araçatuba & Entre os municípios da própria AU. \\
\hline $\begin{array}{l}\text { 7-MR São João da } \\
\text { Boa Vista }\end{array}$ & Com os municípios da microrregião da Mogiana. \\
\hline $8-$ MR Mogiana & Com os municípios das microrregiões de São João da Boa Vista \\
\hline $9-$ MR Estâncias & Com os municípios da microrregião Bragantina. \\
\hline $10-$ MR Bragantina & Com os municípios da microrregião das Estâncias. \\
\hline $11-$ MR São Roque & Com municípios da AU de Sorocaba. \\
\hline
\end{tabular}




\begin{tabular}{l|l}
\hline 12 - MR Vale do Ribeira & $\begin{array}{l}\text { É uma microrregião extensa, porém com baixa densidade } \\
\text { demográfica, o que desfavorece o ganho de escala. Sugere-se } \\
\text { atenção especial - apoio técnico, investimentos financeiros } \\
\text { e incentivos fiscais - por parte do poder público, tanto na } \\
\text { busca de soluções compartilhadas para resíduos sólidos, } \\
\text { quanto na busca de soluções individuais para os municípios da } \\
\text { microrregião. }\end{array}$ \\
\hline 13 - MR Franca & Entre os municípios da própria AU. \\
\hline $14-$ MR Botucatu & Com os municípios da microrregião de Avaré. \\
\hline $15-$ MR Itapetininga & $\begin{array}{l}\text { Sugere-se que: os munićpios da parte nordeste da microrregião } \\
\text { associem-se aos municípios da AU de Sorocaba; os municípios } \\
\text { da parte noroeste associem-se aos municípios da microrregião } \\
\text { de Avaré; e que os municípios da parte central e sul da } \\
\text { microrregião associem-se entre si. }\end{array}$ \\
\hline $16-$ MR Barretos & Entre os municípios da própria AU. \\
\hline $17-$ MR Catanduva & Com os municípios da AU de São José do Rio Preto. \\
\hline $18-$ MR Lins & Com os municípios da microrregião de Marília. \\
\hline $19-$ MR Marília & Entre os municípios da própria AU. \\
\hline $20-$ MR Avaré & Com os municípios da microrregião de Botucatu. \\
\hline $21-$ MR Ourinhos & Entre os municípios da própria AU. \\
\hline $22-$ MR Votuporanga & Entre os municípios da própria AU. \\
\hline $23-$ MR Andradina & Com os municípios da microrregião de Dracena. \\
\hline $24-$ MR Dracena & Com os municípios das microrregiões de Andradina e Marília. \\
\hline Prudente & Entre os municípios da própria AU. \\
\hline Fonte: Adaptado de SMA (SÃo PAULO, 2014).
\end{tabular}

Vale ressaltar que no PRS-SP definiu-se que o recorte para esta proposta não incluiria as Regiões Metropolitanas (São Paulo-RMSP, Campinas-RMC e Vale do Paraíba e Litoral Norte-RMVPLN), no entanto consideram-se convenientes alguns subarranjos, tais como: 1) RMSP: São Paulo Capital; Santo André, São Bernardo do Campo, São Caetano do Sul e Diadema; Mogi das Cruzes e Suzano; Barueri e Osasco; Guarulhos; 2) RMVPLN: Jacareí, São José dos Campos e Taubaté; Litoral Norte; 3) RMC: Campinas; Paulínia; demais municípios pertencentes à RMC. (SÃO PAULO, 2014).

Apesar de apresentarem essa proposta, no próprio PRS-SP, declara-se a necessidade imprescindível de aprofundamento da proposta por eles apresentada, considerando que reconhecem que no PRS-SP não estão esgotadas as necessidades de avaliação com relação à organização da gestão, tampouco no que diz respeito à participação e controle social no processo. 
Nathalia Machado Simão | Francisco César Dalmo

Silvia Azucena Nebra | Paulo Henrique de Mello Sant'Ana

\section{METODOLOGIA}

Como forma de delimitar o escopo da pesquisa, o Estado de São Paulo foi selecionado para a avaliação que aqui será apresentada.

De maneira mais ampla, a expectativa é que os resultados desta pesquisa auxiliem na identificação de outras formas de tratamento e destinação final dos RSU, que não a simples disposição em aterros sanitários. Nesse sentido é considerado o potencial de geração de energia elétrica a partir de biogás, syngas ou de queima direta, utilizando sistemas de ciclos a vapor. Considerando a necessidade de ganhos de escala e minimização dos custos para a geração de energia a partir dos RSU, foi traçado um diagnóstico da situação atual dos arranjos intermunicipais do Estado de São Paulo.

A necessidade de se pensar soluções conjuntas é evidente, justamente porque a gestão de RSU é de responsabilidade municipal, e 569 municípios $(88,21 \%)$ dos 645 municípios existentes no Estado de São Paulo apresentam faixa populacional menor que 100 mil habitantes. (INSTITUTO BRASILEIRO DE GEOGRAFIA E ESTATÍSTICA, 2015). Sem considerar análises mais aprofundadas, essas duas informações comprovam que, pelo menos para esses municípios, a gestão individual adequada que inclua aproveitamento energético seria economicamente inexecutável. Por isso, como visto anteriormente, a gestão consorciada torna-se imprescindível para lidar com a questão.

Os arranjos que são apresentados como resultado da pesquisa foram desenvolvidos a partir da análise preliminar dos arranjos intermunicipais já estabelecidos na forma de consórcios no Estado de São Paulo vigentes em 2016.

A pesquisa acerca dos consórcios partiu inicialmente do levantamento apresentado no Plano Estadual de Resíduos Sólidos de São Paulo (SÃO PAULO, 2014), do SNIS (BRASIL, 2016) e do Observatório de Consórcios Públicos (OCPF, 2016). Foram selecionados os Consórcios que apresentavam como finalidade aspectos relacionados ao meio ambiente, resíduos, saneamento e recursos hídricos.

Após esse primeiro levantamento, e considerando que nenhuma dessas referências apresentava dados atualizados, foi confirmada a existência e efetiva atividade de cada um deles em 2016, por meio 
de pesquisas na internet e de contato telefônico com os municípios que integravam os consórcios identificados inicialmente. Essa iniciativa possibilitou constatar, efetivamente, que havia um total de 21 consórcios atuantes nessas atividades, o que será apresentado nos resultados deste trabalho.

Além dos consórcios, fez-se, também, uma sondagem sobre a taxa de geração de resíduos (COMPANHIA DE TECNOLOGIA DE SANEAMENTO AMBIENTAL, 2016) dos agrupamentos e a população total envolvida. (INSTITUTO BRASILEIRO DE GEOGRAFIA E ESTATÍSTICA, 2016).

Tais resultados são apresentados principalmente em forma de mapas, sendo que foi utilizado o software QGIS (QGIS DEVELOPMENT TEAM, 2016) para seu desenvolvimento. Bezerra (2015, p. 129) destaca a importância da utilização de "Geotecnologias na representação de informações e análise voltadas à Gestão de Resíduos Sólidos". A destinação final atual dos municípios do Estado de São Paulo disponível no Inventário Estadual de Resíduos Sólidos Urbanos 2015 (COMPANHIA DE TECNOLOGIA DE SANEAMENTO AMBIENTAL, 2016) também foi representada na forma de mapa para compor e facilitar o diagnóstico geral de Gestão dos RSU do Estado de São Paulo.

\section{RESULTADOS E DISCUSSÃO}

O principal objetivo desse levantamento foi o de identificar as sinergias já existentes entre os municípios do Estado, considerando a possibilidade de os consórcios - que não têm como objeto de atuação a gestão de RSU - inserirem em seu escopo de trabalho essa atividade. Assim, estão apresentados, na Tabela 2, os consórcios da área ambiental que estão em funcionamento atualmente, bem como a soma populacional e a de geração dos RSU nos municípios que compõem cada um dos consórcios identificados na pesquisa. 
Nathalia Machado Simão | Francisco César Dalmo Silvia Azucena Nebra | Paulo Henrique de Mello Sant'Ana

Tabela 2 - Consórcios da área ambiental e somatória populacional e dos RSU dos municípios consorciados

\begin{tabular}{|c|c|c|c|c|}
\hline $\begin{array}{l}\text { Nome do } \\
\text { Consórcio }\end{array}$ & $\begin{array}{l}\text { Número de } \\
\text { Municípios } \\
\text { Participantes }\end{array}$ & Municípios & $\begin{array}{l}\text { Total } \\
\text { RSU } \\
\text { (ton. } \\
\text { dia-1) }^{1} \\
\end{array}$ & $\begin{array}{c}\text { Total } \\
\text { População }\end{array}$ \\
\hline 1 - CISBRA & 12 & $\begin{array}{l}\text { Águas de Lindóia, Amparo, Itapira, } \\
\text { Lindóia, Monte Alegre do Sul, } \\
\text { Morungaba, Pedra Bela, Pinhalzinho, } \\
\text { Santo Antônio de Posse, Serra } \\
\text { Negra, Socorro, Tuiuti. }\end{array}$ & 188,5 & 309.340 \\
\hline 2 - CEDEPAR & 3 & Botucatu, Itatinga, Pardinho. & 136,9 & 167.174 \\
\hline 3 - CONDEMAT & 11 & $\begin{array}{l}\text { Arujá, Biritiba Mirim, Ferraz de } \\
\text { Vasconcellos, Guararema, Guarulhos, } \\
\text { Itaquaquecetuba, Mogi das Cruzes, } \\
\text { Poá, Salesópolis, Santa Isabel, } \\
\text { Suzano. }\end{array}$ & $2.779,1$ & 2.930 .311 \\
\hline $4-\mathrm{CIAS}$ & 6 & $\begin{array}{l}\text { Cajamar, Campo Limpo Paulista, } \\
\text { Jundiaí, Louveira, Várzea Paulista, } \\
\text { Vinhedo. }\end{array}$ & 662,0 & 796.839 \\
\hline 5 - CONSAB & 7 & $\begin{array}{l}\text { Artur Nogueira, Conchal, } \\
\text { Cordeirópolis, Cosmópolis, } \\
\text { Engenheiro Coelho, Holambra, } \\
\text { Jaguariúna. }\end{array}$ & 177,8 & 255.774 \\
\hline $\begin{array}{l}6- \\
\text { CONSIMARES }\end{array}$ & 7 & $\begin{array}{l}\text { Capivari, Elias Fausto, Hortolândia, } \\
\text { Monte Mor, Nova Odessa, Santa } \\
\text { Bárbara D'oeste, Sumaré. }\end{array}$ & 736,6 & 864.396 \\
\hline 7 - CIVAP & 24 & $\begin{array}{l}\text { Assis, Borá, Campos Novos Paulista, } \\
\text { Cândido Mota, Cruzália, Echaporã, } \\
\text { Florínea, Ibirarema, lepê, João } \\
\text { Ramalho, Lutécia, Maracaí, Nantes, } \\
\text { Ocauçu, Oscar Bressane, Palmital, } \\
\text { Paraguaçu Paulista, Pedrinhas } \\
\text { Paulista, Platina, Quatá, Rancharia, } \\
\text { Santa Cruz do Rio Pardo, Taciba, } \\
\text { Tarumã. }\end{array}$ & 266,9 & 381.721 \\
\hline $8-A B C$ & 7 & $\begin{array}{l}\text { Diadema, Mauá, Ribeirão pires, Rio } \\
\text { Grande da Serra, Santo André, São } \\
\text { Bernardo do Campo, São Caetano } \\
\text { do Sul. }\end{array}$ & $2.733,2$ & 2.736 .683 \\
\hline $9-$ CIMA & 6 & $\begin{array}{l}\text { Avanhandava, Getulina, Guaiçara, } \\
\text { Lins, Promissão, Sabino. }\end{array}$ & 110,7 & 157.222 \\
\hline
\end{tabular}


A POLÍTICA NACIONAL DE RESÍDUOS SÓLIDOS E A ESTRATÉGIA DE FORMAÇÃO DE CONSÓRCIOS PÚBLICOS INTERMUNICIPAIS

\begin{tabular}{|c|c|c|c|c|}
\hline 10 - CODIVAR & 24 & $\begin{array}{l}\text { Apiaí, Barra do Chapéu, Barra do } \\
\text { Turvo, Cajati, Cananéia, Eldorado, } \\
\text { Iguape, Ilha Comprida, Iporanga, } \\
\text { Itanhaém, Itaóca, Itapirapuã Paulista, } \\
\text { Itariri, Jacupiranga, Juquiá, Juquitiba, } \\
\text { Miracatu, Pariquera-Açu, Pedro } \\
\text { de Toledo, Peruíbe, Registro, São } \\
\text { Lourenço da Serra, Sete Barras, } \\
\text { Tapiraí. }\end{array}$ & 324,2 & 540.181 \\
\hline $11-$ CIPP & 5 & $\begin{array}{l}\text { Álvares Machado, Narandiba, } \\
\text { Pirapozinho, Sandovalina, Tarabai. }\end{array}$ & 44,8 & 67.607 \\
\hline 12 - CODIVAP & 44 & $\begin{array}{l}\text { Aparecida, Arapeí, Areias, Bananal, } \\
\text { Caçapava, Cachoeira Paulista, } \\
\text { Campos do Jordão, Canas, } \\
\text { Caraguatatuba, Cruzeiro, Cunha, } \\
\text { Guararema, Guaratinguetá, Igaratá, } \\
\text { Ilhabela, Jacareí, Jambeiro, } \\
\text { Lagoinha, Lavrinhas, Lorena, Mogi } \\
\text { das Cruzes, Monteiro Lobato, } \\
\text { Natividade da Serra, Nazaré Paulista, } \\
\text { Paraibuna, Pindamonhangaba, } \\
\text { Piquete, Potim, Queluz, Redenção } \\
\text { da Serra, Roseira, Salesópolis, Santa } \\
\text { branca, Santa Isabel, Santo Antônio } \\
\text { do Pinhal, São Bento do Sapucaí, } \\
\text { São José do Barreiro, São José dos } \\
\text { Campos, São Luiz do Paraitinga, } \\
\text { São Sebastião, Silveiras, Taubaté, } \\
\text { Tremembé, Ubatuba. }\end{array}$ & $2.547,8$ & 3.024 .096 \\
\hline $13-\mathrm{CIRL}$ & 3 & Alto Alegre, Barbosa, Penápolis. & 54,0 & 73.763 \\
\hline 14 - CONISUD & 8 & $\begin{array}{l}\text { Cotia, Embu das Artes, Embu-Guaçu, } \\
\text { Itapecerica da Serra, Juquitiba, São } \\
\text { Lourenço da Serra, Taboão da Serra, } \\
\text { Vargem Grande Paulista. }\end{array}$ & 954,1 & 1.106 .685 \\
\hline 15 - CERISO & 32 & $\begin{array}{l}\text { Alambari, Anhembi, Araçariguama, } \\
\text { Araçoiaba da serra, Bofete, Boituva, } \\
\text { Botucatu, Cabreúva, Capela do Alto, } \\
\text { Cerquilho, Cesário Lange, Conchas, } \\
\text { Ibiúna, Iperó, Itu, Jumirim, Laranjal } \\
\text { Paulista, Mairinque, Pereiras, } \\
\text { Piedade, Porangaba, Porto Feliz, } \\
\text { Quadra, Salto, Salto de Pirapora, } \\
\text { São Roque, Sarapuí, Sorocaba, } \\
\text { Tatuí, Tietê, Torre de Pedra, Vargem } \\
\text { Grande Paulista. }\end{array}$ & $1.643,6$ & 2.026 .175 \\
\hline 16 - CIOESTE & 8 & $\begin{array}{l}\text { Barueri, Carapicuíba, Cotia, Itapevi, } \\
\text { Jandira, Osasco, Pirapora do Bom } \\
\text { Jesus, Santana de Parnaiba. }\end{array}$ & $1.994,3$ & 2.083 .317 \\
\hline
\end{tabular}


Nathalia Machado Simão | Francisco César Dalmo

Silvia Azucena Nebra | Paulo Henrique de Mello Sant'Ana

\begin{tabular}{|c|c|c|c|c|}
\hline 17 - CONIRPI & 4 & Cabreúva, Indaiatuba, Itu, Salto. & 480,2 & 566.413 \\
\hline 18 - COMAN & 30 & $\begin{array}{l}\text { Altinópolis, Aramina, Batatais, } \\
\text { Brodowski, Buritizal, Cravinhos, } \\
\text { Cristais Paulista, Franca, Guaíra, } \\
\text { Guará, Igarapava, Ipuã, Itirapuã, } \\
\text { Ituverava, Jardinópolis, Jeriquara, } \\
\text { Miguelópolis, Morro Agudo, } \\
\text { Nuporanga, Orlândia, Patrocínio } \\
\text { Paulista, Pedregulho, Restinga, } \\
\text { Ribeirão Corrente, Rifaina, Sales } \\
\text { Oliveira, Santo Antônio da Alegria, } \\
\text { São Joaquim da Barra, São José da } \\
\text { Bela Vista, Serrana. }\end{array}$ & 745,6 & 969.578 \\
\hline 19 - AMVAPA & 19 & $\begin{array}{l}\text { Águas de Santa Bárbara, Angatuba, } \\
\text { Avaré, Barão de Antonina, Cerqueira } \\
\text { César, Coronel Macedo, Fartura, } \\
\text { laras, Itaberá, Itaí, Itaporanga, } \\
\text { Manduri, Paranapanema, Piraju, } \\
\text { Riversul, Sarutaiá, Taguaí, } \\
\text { Taquarituba, Tejupá. }\end{array}$ & 207,4 & 339.722 \\
\hline $20-$ CIPAS & 2 & Biritiba-Mirim, Salesópolis. & 28,8 & 48.276 \\
\hline $\begin{array}{l}21- \\
\text { CONDERSUL }\end{array}$ & 16 & $\begin{array}{l}\text { Apiaí, Barra do Chapéu, Bom } \\
\text { Sucesso de Itararé, Buri, Campina } \\
\text { do Monte Alegre, Capão Bonito, } \\
\text { Guapiara, Itaóca, Itapeva, Itapirapuã } \\
\text { Paulista, Itararé, Nova Campina, } \\
\text { Ribeirão Branco, Ribeirão Grande, } \\
\text { Riversul, Taquarivaí. }\end{array}$ & 186,2 & 322.316 \\
\hline $22-\mathrm{CIGA}$ & 3 & Elias Fausto, Indaiatuba, Monte Mor. & 257,0 & 308.943 \\
\hline 23 - CIMBAJU & 5 & $\begin{array}{l}\text { Caieiras, Cajamar, Francisco Morato, } \\
\text { Franco da Rocha, Mairiporã. }\end{array}$ & 467,5 & 581.464 \\
\hline
\end{tabular}

Fonte: Elaborada pelos autores (2016), com base em COMPANHIA DE TECNOLOGIA DE SANEAMENTO AMBIENTAL. Inventário estadual de resíduos sólidos urbanos - 2015. São Paulo, 2016. Disponível em: <http://residuossolidos.cetesb.sp.gov.br/wp-content/uploads/sites/36/2013/11/ inventario-RSD-2015.pdf>. Acesso em: 6 set. 2016; INSTITUTO BRASILEIRO DE GEOGRAFIA E ESTATÍSTICA. Estimativas populacionais para os municípios e para as Unidades da Federação brasileiros em 01.07.2016. Rio de Janeiro, 2016. Disponível em: <http://www.ibge.gov.br/home/estatistica/populacao/estimativa2016/estimativa_dou.shtm>. Acesso em: 13 set. 2016.

Notas: 1 - CETESB

$$
2 \text { - IBGE }
$$

A quantidade de geração de resíduos de cada um dos consórcios está relacionada diretamente com a população dos municípios consorciados, sendo que, não necessariamente, o consórcio com o maior número de municípios é o que gera maior volume de resíduos. Como exemplo, o caso do Consórcio de Desenvolvimento Intermunicipal do Vale do Ribeira (CODIVAR) e do Consórcio Intermuni- 
cipal do Vale do Paranapanema (CIVAP) que, apesar de contarem com 24 municípios, cada um deles gera, respectivamente, 324,22 e 266,87 ton.dia-1, enquanto o Consórcio Intermunicipal da Região Sudoeste da Grande São Paulo (CONISUD) e o Consórcio Intermunicipal da Região Oeste Metropolitana de São Paulo (CIOESTE), que contam com apenas 8 municípios, geram respectivamente 954,07 e 1.994,31 ton.dia ${ }^{-1}$.

Alguns arranjos como o Consórcio Intermunicipal das Bacias dos rios Piracicaba, Capivari e Jundiaí (PCJ), Associação dos Municípios da Araraquarense (AMA) e Consórcio Intermunicipal Tietê-Paraná (CITP) não foram considerados, uma vez que apresentam um número excessivo de municípios participantes, e, dessa forma, não seriam relevantes para a análise sobre gestão de RSU consorciada, em questão. A composição dos consórcios apresentados na tabela acima está representada na Figura 6.

Figura 6 - Consórcios de Meio Ambiente existentes no Estado de São Paulo

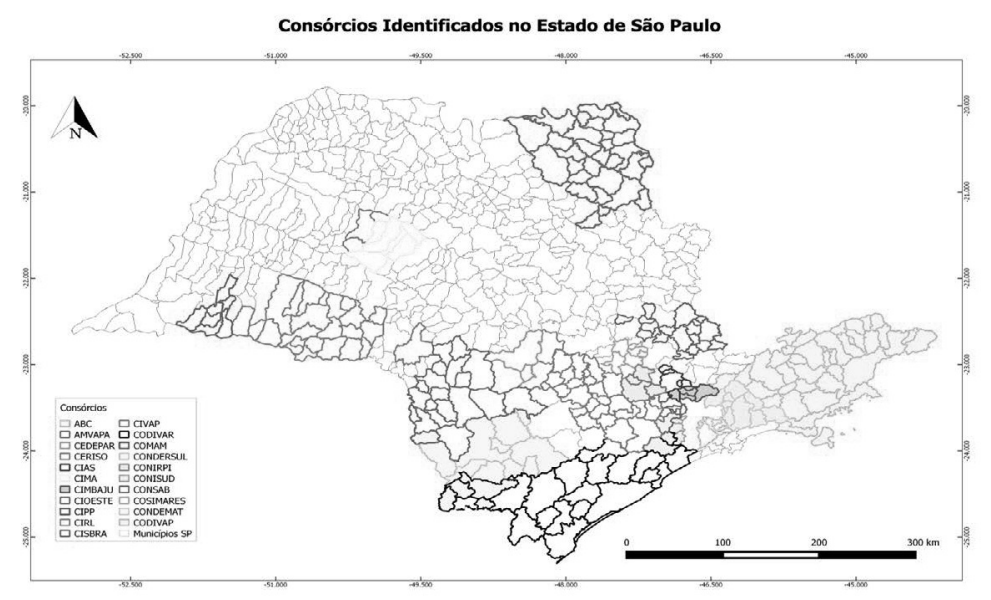

Fonte: Elaborada pelos autores (2016), conforme informações das Prefeituras.

Na comparação com o levantamento de 2012, publicado no PRS-SP em 2014 (SÃO PAULO, 2014), é possível verificar que houve uma redução significativa dos consórcios da área de meio ambiente em atividade. Alguns deles foram extintos e outros simplesmente existem formalmente, mas não são atuantes. A Região Noroeste do Estado é a que apresenta maior ausência de sinergias, 
enquanto as Regiões Sul e Sudeste possuem o maior número de municípios envolvidos em consórcios intermunicipais.

Rompimento abrupto entre um parágrafo e outro. Ademais, o assunto já foi mencionado no último § da pág. 12.

Destaca-se, assim, a distribuição geográfica dos municípios que dispõem seus resíduos em Piratininga, Guatapará e Caieiras. Dos treze municípios que dispõem em Piratininga, o município de Lins dista aproximadamente $122 \mathrm{~km}$ do aterro. Dos dezenove que dispõem em Guatapará, o município de Águas de Prata dista aproximadamente $189 \mathrm{~km}$. Por fim, dos municípios que dispõem em Caieiras, os localizados no Vale do Ribeira como Iguape, Ilha Comprida e Sete Barras ficam a uma distância média aproximada de $220 \mathrm{~km}$ do local de destinação final. (SÃO PAULO, 2016). A disposição atual está apresentada na Figura 7.

Figura 7 - Municípios que exportam RSU e local de destinação

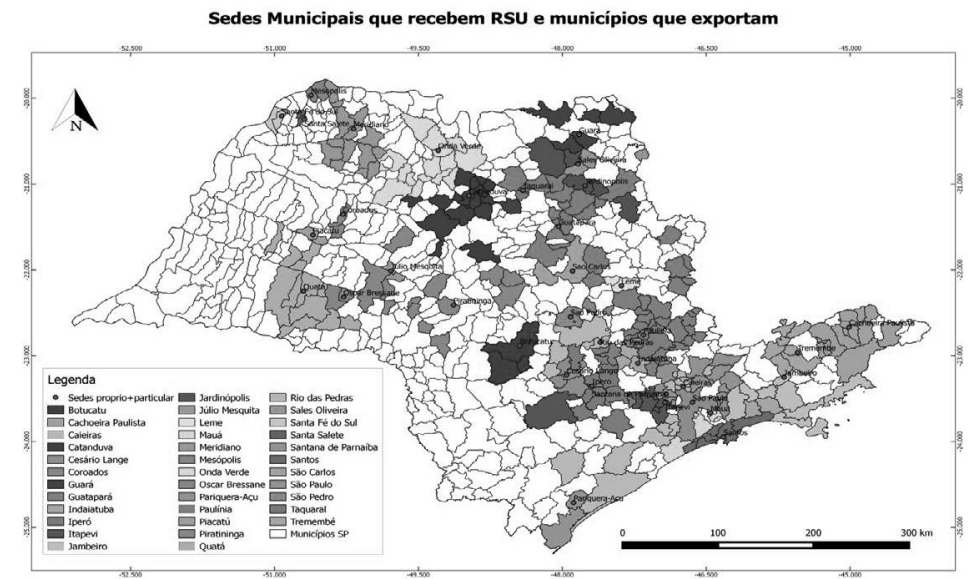

Fonte: Elaborada pelos autores (2016), com base em CETESB (2016).

Nesse sentido, essa distribuição geográfica e de logística de transporte dos resíduos atualmente vigentes no estado de São Paulo, desde a sua geração até a destinação final, já seriam elementos suficientes para um maior aprofundamento das discussões sobre os consórcios ou arranjos municipais, com o objetivo de reduzir os custos de operação e contribuir para menor consumo de combustível e consequente emissão de gases do efeito estufa, colaborando, desse 
modo, para a diminuição de despesas municipais e para uma destinação final ambientalmente adequada dos RSU conforme preconiza a PNRS

\section{CONCLUSÃO}

Apesar de a PNRS e o PRS-SP terem trazido avanços no que se refere à idealização da gestão dos RSU no Brasil e no Estado de São Paulo, o planejamento está ainda muito aquém de apresentar propostas práticas que, de fato, orientem e direcionem os municípios para que seus objetivos sejam atingidos.

Conforme apresentado na introdução, a destinação final dos RSU ambientalmente adequada não é realizada por grande parte dos municípios brasileiros e paulistas. O PRS-SP buscou indicar algumas propostas de soluções compartilhadas para as AU e MR do Estado de São Paulo e demarcadas pela EMPLASA, em 2011. As recomendações realizadas são, no entanto, carentes de detalhes capazes de orientar um processo mais estruturado para a efetivação do plano.

Considerando que a formação dos consórcios públicos é reconhecidamente uma forma de solução mais efetiva para lidar com a gestão de RSU dos municípios, o levantamento realizado nesta pesquisa pôde esclarecer em que ponto se situa a gestão pública municipal relacionada a essa temática. Ao comparar o levantamento realizado com a pesquisa sobre consórcios do PRS-SP, identificou-se que ao invés de as soluções consorciadas terem aumentado/evoluído, o que seria interessante para a gestão municipal dos RSU, o inverso aconteceu. Além de alguns dos consórcios já existentes terem sido extintos ou estarem inativos, nenhuma outra proposta de solução compartilhada para gestão de RSU foi criada desde 2012 até 2016.

Foram identificados ao todo 23 consórcios envolvidos com a questão ambiental, que englobam 263 municípios do Estado de São Paulo - o que representa 40\% do total. Dos 23 identificados, 11 estão envolvidos com o tema de gestão de resíduos e somam somente 80 municípios dos 645 paulistas. A Região Noroeste do Estado apresentou maior ausência de sinergias intermunicipais, enquanto as Regiões Sul, Sudeste e Leste representaram o maior número de municípios envolvidos em consórcios intermunicipais.

Identificou-se, também, que em diferentes regiões do Estado de São Paulo existem situações onde a distância entre a geração 
e a disposição final dos RSU é significativamente alta (como nos exemplos da disposição em Caieiras, Guatapará e Piratininga). Essa situação não é, portanto, pontual, mas sim reflete a falta de planejamento não só sobre a gestão dos RSU, como também sobre a simples destinação dos RSU nos aterros sanitários do Estado.

Propõe-se que uma avaliação mais aprofundada dos motivos pelos quais estas longas distâncias têm sido percorridas pelos RSU seja realizada, no intuito de considerar a possibilidade de disposição em suas sedes ou em locais mais próximos. Independente das restrições (sejam ambientais, econômicas etc.) que impedem essa disposição mais eficaz, vale ressaltar que a destinação em aterros sanitários não é a única forma de dispor os resíduos, apesar de ser a mais usual no Brasil e no Estado de São Paulo.

Ora, a verificação sobre as distâncias que os RSU têm percorrido nos levam a questionar por quanto tempo ainda é possível manter os aterros sanitários como principal meio de disposição final dos RSU. Seja por sermos um país de grande extensão territorial ou porque esta forma de destinação é a mais viável economicamente (motivos usualmente utilizados para manter a priorização pela destinação em aterros sanitários), os fatos nos levam a considerar indícios de instabilidade na execução do programa.

Aponta-se, portanto, a necessidade de desenvolvimento de outras formas de tratamento e destinação final dos RSU, como a reciclagem, a compostagem e a instalação de plantas de recuperação energética através da queima ou digestão anaeróbia, como forma de tratamento e destinação final dos RSU no Brasil e no Estado de São Paulo.

\section{REFERÊNCIAS}

ANJOS, P. A. dos. Consórcios Públicos de Resíduos Sólidos Urbanos: estudo de caso no Estado do Paraná. 2014. 122 f. Dissertação (Mestrado em Meio Ambiente Urbano e Industrial) - Setor de Tecnologia, Universidade Federal do Paraná, Curitiba, 2014. Em parceria com o SENAI/PR e a Universität Stuttgart.

ASSOCIAÇÃO BRASILEIRA DE EMPRESAS DE LIMPEZA PÚBLICA E RESÍDUOS ESPECIAIS. Panorama dos resíduos sólidos no Brasil 2014. São Paulo, 2014. Disponível em:<http:// 
www.abrelpe.org.br/Panorama/panorama2014.pdf >..Acesso em: 14 jan. 16.

BEZERRA, J. P. P. A gestão integrada de resíduos sólidos urbanos na UGRHI-14 Alto Paranapanema: interfaces concretas e potencialidade. 2015. $400 \mathrm{f}$. Tese (Doutorado em Geografia) - Faculdade de Ciências e Tecnologia, Universidade Estadual Paulista, Presidente Prudente, 2015.

BRASIL. Presidência da República. Lei $n^{\circ}$ 11.107, de 6 de abril de 2005. Dispõe sobre normas gerais de contratação de consórcios públicos e dá outras providências. Diário Oficial da União, Brasília, DF, 7 abr. 2005. Seção 1, p. 1.

Presidência da República. Lei no 12.305, de 2 de agosto de 2010. Institui a Política Nacional de Resíduos Sólidos; altera a Lei $\mathrm{N}^{\circ}$ 9.605, de 12 de fevereiro de 1998; e dá outras providências. Diário Oficial da União, Brasília, DF, 3 ago. 2010. Seção 1, p. 3.

Secretaria Nacional de Saneamento Ambiental. Sistema Nacional de Informações sobre Saneamento: diagnóstico do manejo de resíduos sólidos urbanos - 2013. Brasília, DF, 2015. Disponível em: $<$ http://www.snis.gov.br/diagnostico-residuossolidos/diagnostico-rs-2013>. Acesso em: 1 mar. 2016.

. Sistema Nacional de Informações sobre Saneamento: diagnóstico do manejo de resíduos sólidos urbanos - 2014. Brasília, DF, 2016. Disponível em: $<$ http://www.snis. gov.br/diagnostico-residuos-solidos/diagnostico-rs-2014>. Acesso em: 1 mar. 2016.

COMPANHIA DE TECNOLOGIA DE SANEAMENTO AMBIENTAL. Inventário estadual de resíduos sólidos urbanos - 2015. São Paulo, 2016. Disponível em: <http:// residuossolidos.cetesb.sp.gov.br/wp-content/uploads/ sites/36/2013/11/inventario-RSD-2015.pdf $>$. Acesso em: 6 set. 2016.

DI PIETRO, M. S. Z. O Consórcio Público na Lei 11.107, de 6.4.2005. Revista Eletrônica de Direito do Estado, Salvador, n. 3, p.1-14, jul./ago./set. 2005.

EMPRESA PAULISTA DE PLANEJAMENTO

METROPOLITANO SA. Rede Urbana e Regionalização do Estado de São Paulo. São Paulo, 2011. Disponível em: $<$ http://produtos.seade.gov.br/produtos/publicacoes/pub 
RedeUrbanaRegionalizacaoESP 2011.pdf>. Acesso em: 5 set. 2016.

FELICORI, T. C. et al. Identificação de áreas adequadas para a construção de aterros sanitários e usinas de triagem e compostagem na mesorregião da Zona da Mata, Minas Gerais. Engenharia Sanitária e Ambiental, Rio de Janeiro, v. 21, n. 3, p. 547-560, jul./set. 2016.

INSTITUTO BRASILEIRO DE GEOGRAFIA E

ESTATÍSTICA. Estimativas populacionais para os municípios e para as Unidades da Federação brasileiros em 01.07.2016. Rio de Janeiro, 2016. Disponível em: <http://www.ibge.gov. br/home/estatistica/populacao/estimativa2016/estimativa_dou. shtm>. Acesso em: 13 set. 2016.

Pesquisa de Informações Básicas Municipais. Perfil dos Municípios Brasileiros 2011. Rio de Janeiro, 2012. Disponível em:<ftp://ftp.ibge.gov.br/Perfil_Municipios/2011/munic2011. pdf $>$. Acesso em: 14 set. 2016.

Perfil dos Municípios Brasileiros 2014. Rio de Janeiro, 2015. Disponível em:<http://biblioteca.ibge.gov.br/ visualizacao/livros/liv95942.pdf>. Acesso em: 14 set. 2016.

MINAS GERAIS. Secretaria de Estado de Desenvolvimento Regional, Política Urbana e Gestão Metropolitana. Relatório de Consórcios de Resíduos Sólidos Urbanos de Minas Gerais. Belo Horizonte, mar. 2016. Disponível em: $<\mathrm{http} / / / \mathrm{www}$. cidades.mg.gov.br/images/NOTICIAS/2016/Relatrio\%20da\%20 pesquisa $\% 20$ com $\% 20$ consrcios $\% 20 \mathrm{de} \% 20 \mathrm{RSU} \% 20-\% 20$ verso\%20pdf.pdf >. Acesso em: 5 set. 2016.

NASCIMENTO NETO, P.; MOREIRA, T.A. Consórcio intermunicipal como instrumento de gestão de resíduos sólidos urbanos em regiões metropolitanas: reflexões teórico-conceituais. Revista Brasileira de Gestão e Desenvolvimento Regional, v. 8, n. 3, p. 239-282, set./dez. 2012.

\section{OBSERVATÓRIO DE CONSÓRCIOS PÚBLICOS E DO}

FEDERALISMO. Consórcios Públicos - Banco de Dados. Rio de Janeiro, 2016. Disponível em:<http://www.ocpf.org.br/consorciospublicos/banco-de-dados/pesquisa/>. Acesso em: 6 set. 2016.

QGIS DEVELOPMENT TEAM. QGIS Geographic Information System. [S. 1.], 2016. Open Source Geospatial Foundation Project. Disponível em: <http://www.qgis.org/>. Acesso em: 25 set. 2016. 
SÃO PAULO. Departamento de Estradas de Rodagem do Estado de São Paulo. Web Rotas. 2016. Disponível em: <http://200.144.30.104/ website/webrota/viewer.htm>. Acesso em: 5 out. 2016.

Secretaria do Meio Ambiente. Plano de resíduos sólidos do

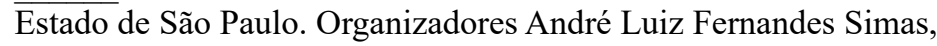
Zuleica Maria de Lisboa Perez. 1. ed. São Paulo: SMA, 2014.

SILVA, W. de M. F. Consórcios públicos na gestão de resíduos sólidos urbanos no Brasil. 2015. 136 f. Dissertação (Mestrado em Gestão Econômica do Meio Ambiente) - Faculdade de Economia, Administração, Contabilidade, Universidade de Brasília, Brasília, DF, 2015.

SUZUKI, J. A. N.; GOMES, J. Consórcios intermunicipais para a destinação de RSU em aterros regionais: estudo prospectivo para os municípios no Estado do Paraná. Engenharia Sanitária e Ambiental, Rio de Janeiro, v. 14, n. 2, p. 155-158, abr./jun. 2009.

\section{Notas}

1“O tratamento adequado dos RSU no Brasil - por meio dos aterros sanitários - era realizado, em 1989 , por $1,1 \%$ dos municípios brasileiros, em 2000 , por $17,3 \%$, em 2008 , por $27,7 \%$ dos municípios (PNSB, 2008), tendo aumentado para 40,2\% em 2014”. (ASSOCIAÇÃO BRASILEIRA DE EMPRESAS DE LIMPEZA PÚBLICA E RESÍDUOS ESPECIAIS, 2014, p. 39).

${ }^{2}$ A divisão se dá em três Regiões Metropolitanas, vinte e duas Microrregiões (MR) e seis Aglomerações Urbanas (AU). De acordo com a Empresa Paulista de Planejamento Metropolitano Sa (EMPLASA, 2011) as divisões foram realizadas a partir de critérios econômicos, demográficos e físico-territoriais. 
